\begin{tabular}{|c|c|c|c|c|}
\hline $\begin{array}{c}\text { 118SHARE: SOCIAL WORK } \\
\text { JURNAL }\end{array}$ & VOLUME: 7 & NOMOR: 1 & HALAMAN: $1-129$ & $\begin{array}{l}\text { ISSN:2339 -0042 }(p) \\
\text { ISSN: } 2528-1577\end{array}(e)$ \\
\hline
\end{tabular}

\title{
DUKUNGAN SOSIAL KELUARGA DALAM MEMENUHI KEBUTUHAN SOSIAL LANSIA DI PANTI
}

\author{
Oleh: \\ Camelia Kristika Pepe ${ }^{1}$, Hetty Krisnani ${ }^{2}$, Dessy Hasanah Siti A. ${ }^{3}$, Meilanny Budiarti \\ Santoso $^{4}$ \\ 1. ASEAN Inter-Parliamentary Assesmbly (AIPA) Secretariat \\ 2. Pusat Studi Kesejahteraan Anak dan Keluarga FISIP-Universitas Padjadjaran \\ 3. Departemen Kesejahteraan Sosial Universitas Padjadjaran \\ 4. Pusat Studi Kesejahteraan Anak dan Keluarga FISIP-Universitas Padjadjaran
}

\section{Email:}

(camelpepe1995@gmail.com; hettykrisnani@yahoo.com; dessyhasanahsitiasiah@yahoo.com; meilannybudiarti13@gmail.com)

\begin{abstract}
Abstrak
Lanjut usia merupakan fase kehidupan yang umumnya akan dilalui oleh setiap manusia. Fase ini merupakan proses dari berkurang dan hilangnya beberapa sumber primer yang mendukung kehidupan lansia, baik sumebr biologis, ekonomi, soaial dan ekonomi. Panti Lansia (wreda atau jompo) disediakn dengan tujuan utama adalah menopang atau mendukung kehidupan lansia. Tidak sedikit para lanjut usia yang tinggal di Panti masih memiliki keluarga, baik keluarga keluarag inti atau keluarga besar. Namun demikian dukungan sosial keluarga tetap diperlukan bagi lansia walau lansia telah berada di Panti. Para lansia perlu dukungan perhargaan, masih membutuhkan informasi tentang perkembangan di luar panti, membutuhkan dukungan ekonomi dan penyaluran minat-bakat, serta masih membutuhkan dukungan sosial lainnya. Ssehingga dukungan sosial dari keluarga sangat penting dalam proses palayanan Lansia di Panti-panti yang ada.
\end{abstract}

Kata kunci: Lanjut usia, dukungan sosial, keluarga.

\section{Pendahuluan}

Lanjut usia atau yang lebih sering disebut dengan lansia merupakan fase kehidupan akhir yang akan dijalankan manusia. Menurut Undang-Undang Nomor 13 Tahun 1998 dalam Bab 1 Pasal 1 ayat 2 lanjut usia adalah seseorang yang mencapai usia enam puluh tahun keatas. Pada tahapan tersebut individu akan mengalami penurunan fungsi fisik dan psikis. Hal ini ditanggulangi dengan adanya kemajuan pengetahuan dan teknologi terutama dalam bidang ilmu kesehatan, penanganan penyakit dan pelayanan kesehatan. Dampak dari hal tersebut adalah kenaikan angka harapan hidup. Berdasarkan sensus penduduk yang dilakukan angka harapan hidup di Indonesia akan mencapai usia 71 tahun. Angka tersebut tentunya diiringi dengan kenaikan jumlah penduduk seperti terlihat pada tabel 1.1 dibawah ini 
Tabel 1.1 Usia Harapan Hidup dan Jumlah Penduduk

\begin{tabular}{|c|c|c|c|}
\hline Tahun & $\begin{array}{c}\text { Usia Harapan } \\
\text { Hidup (tahun) }\end{array}$ & $\begin{array}{c}\text { Jumlah } \\
\text { Lanjut Usia }\end{array}$ & Proporsi \\
\hline 1980 & 52,2 & 7.998 .543 & $5,45 \%$ \\
\hline 1990 & 59,8 & 11.277 .557 & $6,29 \%$ \\
\hline 2000 & 64,5 & 14.439 .967 & $7,18 \%$ \\
\hline 2010 & 67,4 & 23.992 .553 & $9,77 \%$ \\
\hline $2020^{*}$ & 71,1 & 28.822 .879 & $11,34 \%$ \\
\hline
\end{tabular}

Sumber: BPS, 2014 (Badan Pusat Statistik) (http://data.menkokesra.go.id/content/pember dayaan-lansia)

Jumlah penduduk yang besar ini jika dikelola dengan baik akan menjadi modal dasar dan aset yang berharga dalam proses pembangunan. Pertambahan penduduk harus diimbangi dengan peningkatan kualitas penduduk karena bila tidak ada perimbangan antara kuantitas dan kualitas maka hal ini akan menjadi masalah dan beban dalam pembangunan.

Peningkatan jumlah penduduk lanjut usia tersebut menimbulkan dampak terhadap berbagai macam aspek kehidupan, baik bagi lanjut usia itu sendiri, keluarga, masyarakat maupun pemerintah. Semakin meningkat angka harapan hidup maka beban ketergantungan usia non produktif terhadap usia produktif akan semakin meningkat pula. Hal ini terjadi lantaran di masa lansia individu akan mengalami beberapa perubahan terkait dengan menurunnya beberapa fungsi diantaranya adalah penurunan fungsi fisik, kognitif, penurunan fungsi dan potensi seksual serta perubahan aspek psikososial. Hal ini akan berhubungan dengan kemandirian lansia itu sendiri. Penurunan fungsi ini membuat lansia harus mendapat prioritas utama dalam penanganannya agar dapat tetap menjalankan fungsi serta kebutuhan jasmani dan rohaninya terpenuhi.

Dalam melangsungkan pemenuhan kebutuhannya pada beberapa lansia memerlukan bantuan orang lain karena penurunan fungsi baik fisik maupun sosial yang terjadi. Hal ini mengacu pada pada UU No.13 Tahun 1998 pasal 1 ayat 4 mengenai kesejahteraan lanjut usia (lansia). Keluarga merupakan orang terdekat yang mengambil posisi penting dalam hidup lansia. Tanpa lansia atau orangtua maka tidak akan ada anak beserta generasi mendatang yang tumbuh. Indonesia sebagai negara yang menganut budaya ke-Timuran masih menjunjung prinsip bahwa merawat orangtua merupakan sebuah kewajiban anak sebagai tanda bakti. Prinsip ini juga dituangkan dalam NKKBS yaitu Norma Kecil Keluarga Bahagia Sejahtera. Dewasa ini keberadaan panti werda mengambil peran penting di masyarakat. Selain karena bergesernya nilai dan pandangan masyarakat terkait keberadaan lansia di dalam rumah, hal ini juga disebabkan karena kebutuhan lansia yang meningkat. Kebutuhan lansia yang meningkat ini salah satunya dipenagruhi oleh gaya hidup. Lansia kalangan urban yang semasa produktifnya lebih banyak melakukan kegiatan bekerja dan menjalin banyak relasi membutuhkan pelayanan panti sebagai sarana untuk menjaga keeksistensian dirinya sekaligus bagian dari pemenuhan kebutuhan sosial. Akan tetapi sebaik-baiknya pelayanan panti, lansia tetap membutuhkan dukungan keluarga untuk memenuhi kebutuhan sosialnya.

\section{Metode}

Metode yang digunakan dalam penelitian ini adalah metode deskriptif dengan pendekatan kualitatif, yaitu agar diperoleh data yang spesifik, lengkap, dan mendalam tentang subyek dan obyek penelitian dari berbagai perspektif yang terkait, sehingga dapat dipaparkan gambaran situasi dan kondisi di lapangan sebagai bahan analisis untuk diambil simpulan.

Sumber data dalam penelitian ini terdiri dari sumber data primer dan sumber data sekunder yang diperoleh dengan menggunakan beberapa teknik pengumbulan data, yaitu wawancara secara mendalam, observasi non partisipatif dan studi kepustakaan terhadap 
berbagai literalur terkait dengan konteks penelitian.

\section{Pembahasan}

Kebutuhan sosial adalah segala sesuatu yang menyangkut kebutuhan untuk berinteraksi dengan sesama dan saling menjaga hubungan. Kebutuhan ini harus dipenuhi dengan memberikan dukungan sosial kepada lansia oleh keluarga karena sebagaimana peran keluarga terhadap lansia adalah merawat generasi. Artinya lansia membutuhkan pemeliharaan dan juga interaksi dengan generasi berikutnya serta kerabat lain di luar keluarga untuk menjaga eksistensi dirinya. Dalam hal ini lansia di panti werdha memiliki hubungan yang baik dengan keluarga dan juga sesama lansia di panti. Berdasarkan hasil penelitian di lapangan ditemukan bahwa lansia memang jarang bertemu langsung dengan keluarganya karena kesibukan dan keterbatasan waktu yang ada. Mereka lebih banyak menjalin komunikasi melalui telepon dan media sosial. Sebagaimana Hurlock dalam teorinya menjelaskan bahwa lansia dan keluarganya memiliki hubungan gentik dan terikat secara emosional. Artinya pertemuan langsung antara lansia dengan keluarganya sangat dibutuhkan meskipun mereka menyatakan tidak ingin merepotkan. Hal ini selayaknya terjadi karena keluarga merupakan sumber dukungan sosial natural. Berdasarkan hasil penelitian maka dukungan sosial keluarga yang diberikan dalam memenuhi kebutuhan sosial tergambar sebagai berikut:

a. Dukungan penghargaan

Dukungan ini diberikan dalam bentuk mengakui keberadaan lansia di panti. Cara yang digunakan untuk mengakui keberadaan lansia di panti adalah dengan melakukan komunikasi. Hasil penelitian menyebutkan bahwa komunikasi yang dilakukan oleh keluarga dengan lansia memang terjadi lebih banyak melalui telepon dan juga media sosial. Akan tetapi ketika ditanya mengenai keberadaan lansia itu sendiri keluarga akan berusaha menjelaskan sebijak mungkin kepada mereka yang bertanya bahwa tinggal di panti adalah alternatif terbaik bagi lansia yang memilih untuk mendapatkan teman, mengusir kesepian dan juga hidup lebih sehat secara fisik. Salah satu ciri lansia adalah memiliki status kelompok minoritas (Hurlock, 1980) karena umumnya mereka lebih ingin didengarkan daripada mendengarkan. Melalui dukungan penghargaan ini komunikasi baik yang dijalin memudahkan lansia untuk memahami diri dan lingkungan sekitarnya sehingga dapat lebih diterima. Mereka juga tetap dapat menjalankan perannya sebagai orangtua dengan memberi nasehat dan saran kepada anakcucunya. Sayangnya komunikasi tersebut lebih banyak dilakukan melalui perantara dengan menggunakan handphone atau meminta bantuan petugas panti sehingga banyak hal yang harusnya tersampaikan menjadi tidak tersampaikan. Misalnya seperti saat lansia bercerita kemudian diberikan tanggapan oleh keluarga umumnya keluarga mengakui lansia rawan tersinggung dengan ucapan keluarga karena perbedaan maksud dan juga tidak melihat ekspresi secara langsung. Akibatnya dukungan yang diberikan bukan memberikan kepuasan secara kebutuhan sosial tetapi justru menjadi berdampak negatif karena dukungan yang tersedia dianggap sebagai sesuatu yang tidak membantu. Selain itu cara keluarga untuk tidak membohongi lansia dengan menyampaikan informasi apa adanya juga termasuk bentuk menghargai keberadaan lansia itu sendiri. Hal ini akan membantu lansia untuk terhindar dari permasalahan di hari tuanya yaitu kecemasan berlebih yang dapaat menimbulkan gangguan kesehatan. Sebisa mungkin keluarga menghargai lansia sebagai orangtua yang harus diakui keberadaannya dan apabila hal ini dilihat secara budaya tentu menghargai orangtua adalah norma yang dijunjung tinggi dalam lingkungan sosial masyarakat Indonesia. Pemberian dukungan aspek penghargaan ini selaras dengan tujuan pelayanan sosial yang salah satunya adalah berupa 
memulihkan dan melindungi kehidupan keluarga. Berdasarkan hasil ecomap meskipun terdapat hubungan yang kurang kuat akibat konflik antara lansia dengan anaknya ketika tinggal di panti hubungan mereka menjadi kuat kembali karena perasaan kehilangan. Akibatnya disini hubungan saling menghargai dan menghormati sebagaimana anak dengan orangtuanya pun terwujud

b. Dukungan instrumental

Dukungan ini mencakup bantuan yang sifatnya nyata. Keluarga mendukung lansia dan segala aktivitasnya di panti. Hal ini dilakukan keluarga karena mereka ingin melihat lansia tidak kesepian dan memiliki banyak teman. Lansia memerlukan waktu juga bersama dengan teman-temannya seperti mengikuti kegiatan di panti yang ditunjang dengan fasilitas pemberian keluarga misalnya scrable dan alat jahit. Harapannya dengan memberikan fasilitas tersebut lansia dapat bergai dan mengisi waktu luang tidak sendiri tetapi bersama dengan temantemannya. Hal ini juga didukung oleh pernyataan Weinberger (2011) yang mengatakan bahwa lansia membutuhkan hubungan sosial dan kegiatan di setiap waktu untuk mengatasi kesunyian dan kekosongan. Keluarga memahami memberikan fasilitas adalah bagian dari sarana mendukung aktivitas lansia di panti sehingga mereka tidak merasa bosan dan sepi. Melalui dukungan instrumental ini upaya keluarga dalam mendukung hubungan antara lansia dengan teman di panti juga terwujud. Tidak hanya itu pemberikan dukungan instrumental juga membuat lansia dapat menjalankan aktifitas di panti karena secara finansial dan administratif keluarga yang membayarkan biaya lansia tinggal di panti baik biaya operasional maupun tambahan lainnya ketika ada rekreasi. Hal ini tentu saja memberikan dampak terhadap apa yang diinginkan lansia yaitu tetap memiliki hubungan sosial yang luas salah satunya adalah dengan tinggal di panti seperti Sasana Tresna Werda Karya
Bhakti ini. Pemeliharaan ikatan keluarga antar generasi adalah salah satu tugas setiap keluarga yang memiliki lansia. Melalui dukungan instrumental dengan memberikan handphone berbasis teknologi terkini dan mengajarkannya kepada lansia dapat membantu mereka memenuhi kebutuhan sosialnya dengan berkomunikasi. Kemajuan teknologi secara teoritis memang menggusur keberadaan lansia yang kurang dapat mengikuti perkembangan teknologi karena kemampuan kognitif yang menurun akan tetapi hal ini tidak berlaku di Sasana Tresna Werda Karya Bhakti karena hampir semua lansia yang ada melek teknologi. Mereka justru memanfaatkan sekali sarana ini untuk berhubungan dengan keluarga dan kerabatnya yang berjauhan

c. Dukungan informasional

Dukungan informasional menurut House (1992) berarti memberikan solusi melalui penyediaan informasi, memberikan saran baik secara langsung maupun tidak langsung dan memberikan umpan balik kepada individu. Berdasarkan hasil penelitian upaya keluarga untuk mendengarkan keluh kesah lansia dan menaati nasehatnya merupakan bentuk dukungan informasional. Meskipun seringkali saran yang diberikan oleh keluarga ini dianggap salah oleh lansia akan tetapi keluarga sudah berusaha menjalankan perannya sebagai guidence (pembimbing) sebagaimana komponen dukungan sosial diberikan kepada lansia. Ketika memiliki masalah berat memang sebijak mungkin keluarga berupaya tidak memberitahu lansia terlebih dahulu namun mereka menghindari untuk berbohong karena menyadari kebutuhan lansia untuk mengethaui dan memberikan feedback untuk menghadapi masalah yang ada. Tidak hanya itu dukungan informasional ini juga diberikan keluarga dengan pelayanan panti yang menyediakan pekerja sosial dan psikolog sebagai wadah lain untuk konseling pada lansia selain dengan keluarga sendiri. 
Akan tetapi karena alasan kenyamanan lansia jarang memanfaatkan dukungan ini dan lebih memilih untuk menunggu keluarganya saat ini bercerita atau mengungkapkan sesuatu

d. Dukungan kelompok atau jaringan sosial Berdasarkan hasil ecomap lansia, hubungan kuat sangat tergambar antara lansia dengan keluarganya terutama anak, cucu dan menantu. Hal ini memang secara teoritis terjadi akibat kelekatan emosional dan genetik diantara keduanya. Selama tinggal di panti tentu lansia memiliki keluarga baru yang terbentuk karena adanya kesamaan aktifitas. Hal ini tentu secara pribadi akan membuat lansia memiliki relasi di luar keluarga inti. Kebutuhan untuk bersosialisasi dan memiliki relasi dengan sesama adalah salah satu aspek kebutuhan sosial lansia. Oleh sebab itu keluarga memberikan kebebasan bagi lansia untuk bergaul dengan siapa pun yang mereka inginkan. Sebagaimana kebutuhan sosial yang menyangkut interaksi keluarga juga tidak pernah berusaha memutus hubungan antara lansia dengan teman-temannya di luar panti. Ketika ada teman lansia yang bertanya terkait keberadaan lansia tersebut maka mereka tidak segan untuk mengajak menengok ke panti atau mengantarkannya. Tidak hanya itu keluarga juga menyertakan lansia dalam acara keluarga seperti pernikahan, arisan dan gathering. Apa yang dilakukan keluarga ini sesuai dengan peran informal keluarga yaitu menjadi penghubung keluarga. Semenjak lansia memasuki fasenya maka berbagai kemunduruan fisik dan psikis yang dialami membuat mereka terbatas ruang geraknya terutama untuk berinteraksi. Akibatnya anak dan cucu sebagai generasi penerus lah yang memelihara dan menghubungkan lansia untuk berinteraksi dengan lingkungan sekitar sebagaimana yang tergambar dalam ecomap mereka. Hal ini tentunya akan menimbulkan perasaan puas tersendiri bagi lansia

\section{Simpulan}

Dukungan sosial dalam memenuhi kebutuhan sosial lansia di panti tergambar dalam cara keluarga untuk memberikan keleluasaan bagi lansia untuk berinteraksi dengan sesamanya baik di panti maupun di luar panti. Keluarga menganggap kehadiran teman bagi lansia membuat mereka bahagia dan mampu terhindar dari stress. Hal ini termasuk ke dalam dukungan sosial kelompok. Bentuk lainnya yaitu keluarga selalu menjadi perantara bagi lansia untuk berhubungan dengan kerabat lain seperti sepupu, keponakan dan juga teman-temannya yang mungkin sudah sulit ditemui. Biasanya keluarga yang akan membawakan pesan atau justru mengantarkan mereka bertemu dengan lansia yang ada di panti. Selain itu dukungan informasional juga diberikan dengan meminta memberikan informasi kepada lansia baik kabar maupun saran agar mereka tetap dapat menjalankan perannya di lingkungan masyarakat. Hal ini dilakukan juga agar mereka merasa terbuang meskipun saran yang diberikan sulit untuk dipahami dan terkadang justru memicu konflik karena lebih banyak disampaikan secara tidak langsung yakni melalui telepon atau konseling dengan petugas panti.

Berdasarkan fenomena ini maka tidak banyak keluarga lansia yang secara rutin melakukan kunjungan langsung ke panti. Biasanya mereka hanya berkomunikasi melalui telepon, video call dan berkirim gambar saja. Oleh sebab itu tidak adanya komunikasi langsung diantara kedua belah pihak seringkali menimbulkan konflik dan percekcokan di keluarga. Akibatnya lansia menjadi mudah sakit, murung dan sedih karena perbedaan pendapat dan komunikasi yang kurang baik maka sebaiknya panti sebagai lembaga pelayanan sosial dapat turut andil membuat jadwal kunjungan rutin keluarga sebagai langkah monitoring kondisi lansia dan keluarganya pula demi keberlangsungan hidup mereka. 


\begin{tabular}{|c|c|c|c|c|}
\hline $\begin{array}{c}\text { 118SHARE: SOCIAL WORK } \\
\text { JURNAL }\end{array}$ & VOLUME: 7 & NOMOR: 1 & HALAMAN: $1-129$ & $\begin{array}{l}\text { ISSN:2339 -0042 }(p) \\
\text { ISSN: } 2528-1577 \\
(e)\end{array}$ \\
\hline
\end{tabular}

\section{Daftar Pustaka}

Azizah, Lilik Ma' rifatul. 2011. Keperawatan Lanjut Usia. Edisi 1. Yogyakarta: Graha Ilmu

Cobb, S. 1987. Social Support as Moderator of live Stress Psycholomatic Medicine. Jurnal of Consulting and Clinical Psychology

http://data.menkokesra.go.id/content/p emberdayaan-lansia

Cutrona, C.E. 1999. Behavior Manifestations of Social Support: Amic Roanalytic Investigation. Journal of Personality and Social Psychology

Hurlock, Elizabeth. 1980. Psikologi Perkembangan Suatu Pendekatan Sepanjang Rentang Kehidupan. Jakarta: Erlangga

http://data.menkokesra.go.id/content/pemberd ayaan-lansia

Koller, Marvin R. 1968. Social Gerontology. New York: Random House

Lalenoh, Tody. 1993. Gerontologi dan Pelayanan Lanjut Usia. Jakarta: Socialia

Lowy, Louis. 1979. Social work With Aging: The Chalenge and Promise of the Later Years. London: Harper \& Row Publish

Lueckenotte. 1997. Pengkajian Gerontologi. Jakarta: EGC

Maliki, Zainuddin. 2003. Narasi Agung: Tiga Teori Sosial Hegemonik. Surabaya: LPAM

Raharjo, ST. 2015. "Pekerjaan Sosial Generalis, Suatu Pengantar Bekerja Bersama Organisasi dan Komunitas", Edisi Revisi Buku, Unpad Press,

Raharjo, ST. 2015. "Dasar Pengetahuan Pekerjaan Sosial", Buku, Unpad Press

Raharjo, ST., Taftazani, BM., Apsari, NC., Santoso, MB. 2016. "PANDUAN PRAKTIKUM MIKRO (Konseling dan Pengembangan Diri)". Buku . Unpad Press.

Raharjo, ST. 2015. "Assessment dan Wawancara dalam Prakti Pekerjaan
Sosial dan Kesejahteraan Sosial”, Edisi Revisi Buku, Unpad Press

Santoso \& Ismail, A. 2009. Memahami Krisis Bagi Lansia. BPK Gunung Mulia, Jakarta

Sarafino, E.P. 2006. Health Psychology: Biopsychosocial Interactions. Fifth Edition. USA: John Wiley \& Sons.

Sarason, I.G., dkk. 1983. Assessing Social Support: The Social Support Questionare. Journal of Personality and Social Psychology 